\title{
Adaptaciones socioambientales ante fenómenos meteorológicos y bélicos a lo largo de la historia de Matamoros, Tamaulipas. México
}

\section{Juan Guillermo Laguna Ortiz}

Doctorante en Filosofía con Orientación en Arquitectura y Asuntos Urbanos. Facultad de Arquitectura de la Universidad Autónoma de Nuevo León (UANL). Correspondencia: Av. Universidad S/N Ciudad Universitaria. San Nicolás de los Garza, Nuevo León, México, lagunaortiz@hotmail.com.

\section{Carlos Estuardo Aparicio Moreno}

Profesor-investigador de tiempo completo. Facultad de Arquitectura de la Universidad Autónoma de Nuevo León (UANL). Correspondencia: Av. Universidad S/N Ciudad Universitaria. San Nicolás de los Garza, Nuevo León, México, caparicio55@yahoo.com.

\section{Eduardo Sousa González}

Profesor-investigador de tiempo completo. Facultad de Arquitectura de la Universidad Autónoma de Nuevo León (UANL). Correspondencia: Av. Universidad S/N Ciudad Universitaria. San Nicolás de los Garza, Nuevo León, México, eduardosousa.gn@uanl.edu.mx.

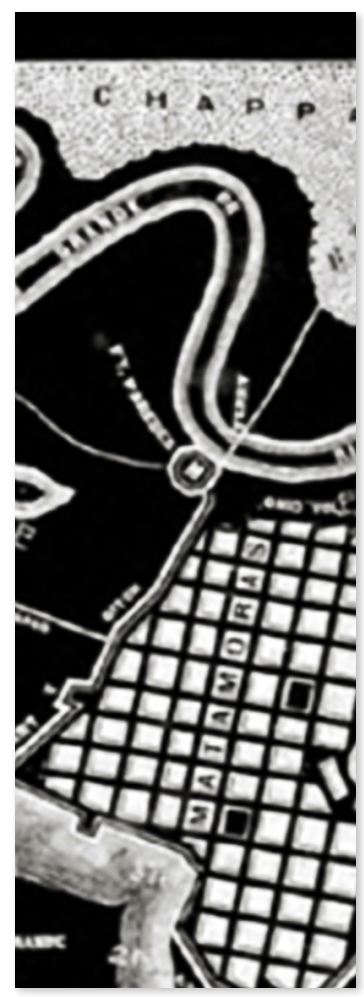

http://dx.doi.org/10.30972/crn.24242921

ISNN 1666-6186. Volumen 24 N. ${ }^{\circ} 24$ (Junio de 2018) pp. 047-072 - Recibido: 02-05-17. Aprobado: 19-03-18 


\title{
Resumen
}

La historia de la ciudad mexicana de Matamoros, Tamaulipas, incluye momentos en que su población ha hecho frente a eventos naturales y bélicos. En este trabajo, tomando en cuenta principios de la teoría de la resiliencia, se presentan cinco períodos que ejemplifican estos sucesos. Primero, desde el nacimiento del poblado en 1519 hasta su papel en la defensa del territorio nacional en 1848. También se trata sobre la capacidad de reacción de la comunidad ante huracanes y embates europeos en la segunda mitad del siglo XIX. Posteriormente, se habla de la adaptabilidad y el crecimiento inesperado tanto de la población como de la ciudad, en los albores del siglo XX, seguido del momento en que se desarrolla la industria maquiladora de 1948 a 1988. Finalmente, nos referimos al proceso de adecuación de Matamoros ante las amenazas meteorológicas y la violencia urbana presentes en esta segunda década del siglo XXI.

\section{Palabras clave}

Adaptaciones socioambientales; fenómenos meteorológicos; fenómenos bélicos; resiliencia; zona costera.

\begin{abstract}
Social and Environmental Adjustments in the Face of Metereological and War Phenomena in the History of Matamoros, Tamaulipas, Mexico

The history of the Mexican city of Matamoros, Tamaulipas, includes moments in which its population has faced natural and war events. In this study, considering the principles of "resilience theory”, five periods are presented to exemplify these kinds of events. Firstly, since the birth of the village in 1519 until the time of its role during the defense of national territory in 1848. In addition, we discuss the community's capacity to react facing hurricanes and European assaults during the second half of the $19^{\text {th }}$ century. Subsequently, we refer to the adaptability and unexpected growth, both of the population and the city, at the beginning of the $20^{\text {th }}$ century, followed by the period when the maquiladora industry developed, between 1948 and 1988. Finally, we refer to the process of adabtabity of Matamoros to overcome the threats and urban violence present in this second decade of the 21st century.
\end{abstract}

\section{Keywords}

Socioenvironmental adaptations; meteorological phenomena; warlike events; resilience; coastal area. 


\section{Adaptaciones socioambientales ante fenómenos meteorológicos y bélicos a lo largo de la historia de Matamoros, Tamaulipas. México}

\section{Introducción}

La ciudad de Matamoros, Tamaulipas, se localiza geográficamente en una zona estratégica por contar con mar y colindar su frontera con los Estados Unidos de América en la región nordeste de México. Además, se ubica en el extremo oriente de la carretera federal número 40, que es la comunicación este-oeste más importante del territorio nacional, que corresponde al eje Matamoros-Mazatlán. Su núcleo urbano, con gran trascendencia histórica en defensa del territorio nacional, está constituido por una zona metropolitana reconocida por su dinámica empresarial en la industria maquiladora, además de sus sectores turístico, educativo y agrícola (CONAPO, 2012: 32). A lo anterior hay que agregar que la ciudad cuenta con infraestructura portuaria construida para una futura actividad petrolera.

A nivel nacional, Matamoros es reconocido como un municipio donde continuamente se desarrollan estrategias de protección civil ante los embates de la naturaleza, tanto en las zonas urbanas a lo largo del río Bravo como en las zonas costeras rurales. Sin embargo, se destaca también que en el sitio se puede apreciar una extrema desigualdad en su distribución socio-espacial, caracterizada por vulnerabilidad y marginación social.

El objetivo de este artículo es conocer cómo la población urbano-rural de la zona costera de Matamoros, Tamaulipas, ha mostrado estrategias de resiliencia, entendiendo esta como la capacidad de los seres humanos para adaptarse positivamente a situaciones adversas frente a desastres, lo cual tiene que ver más con las capacidades de recuperación que de resistencia, más con las adaptaciones sociales y ambientales ante las embestidas de fenómenos meteorológicos y bélicos a lo largo su historia. Para esto hay que preguntarse: ¿cuáles son las características de los embates meteorológicos y bélicos que impactaron la zona de Matamoros?; ¿cuáles son los contextos propios que permitieron a los pobladores de Matamoros adaptarse y recuperarse a las consecuencias ambientales y de guerra? Además, considerando la evolución histórica en la ciudad de Matamoros, es importante conocer ¿cómo la resiliencia desde el punto de vista del desarrollo se puede comprender como un proceso y no como un resultado?, ¿cómo se aprecian cartográficamente las consecuencias de los fenómenos naturales en el tiempo?

Este documento está compuesto por el presente capítulo introductorio, seguido de otro conceptual que aborda el origen de la problemática socio-ambiental y de los fenómenos bélicos. 
A continuación se expone un capítulo que aborda cinco períodos clave del crecimiento de la ciudad de Matamoros, relacionados con la problemática planteada, y finaliza con la conclusión. Cabe agregar que en esta investigación se utiliza el método histórico, el cual es analítico-sintético, ya que para el análisis de los sucesos que se describen en este artículo se hace una descomposición de las partes de cada evento, para que una vez conociendo las posibles raíces, la síntesis permita explicar el hecho histórico (Delgado, 2010). Por tanto, el proceso metodológico de este trabajo incluyó la recopilación de información bibliográfica para fundamentar conceptualmente este documento, así como la búsqueda de fuentes secundarias tanto escritas y como cartográficas. Las variables de análisis utilizadas en este trabajo son las características de los embates meteorológicos y bélicos que impactaron la zona de estudio, los contextos que permitieron a los pobladores de Matamoros adaptarse y recuperarse ante dichos eventos, las manifestaciones del proceso de recuperación, así como la expresión cartográfica en el tiempo. Referente a la cuantificación de los cambios, los indicadores son diversos, ya que unas veces se manifiestan con la construcción de elementos físicos y otras, en acciones ciudadanas.

Las etapas incluyen, en primer lugar, el proceso de adecuación de los pobladores desde la colonización del sitio, en el siglo XVI, hasta la defensa territorial contra ejércitos estadounidenses en 1848. Posteriormente, se aborda la capacidad de regresar a condiciones de relativa estabilidad durante la segunda parte del siglo XIX, cuando la población hace frente a embates bélicos franceses y huracanes. En tercer lugar, se tratan las estrategias urbanas de recuperación en la primera década del siglo XX y la llamada "época de oro del algodón”. A continuación, se habla de los fenómenos meteorológicos en esta ciudad fronteriza durante su transición a la industria maquiladora, de 1948 a 1988. Finalmente, se describe la situación ante los retos que implica la violencia urbana entre 1990 y la segunda década del siglo XXI.

Para Manyena (2006) los principios de la teoría de la resiliencia frente a desastres de escala comunitaria aparecen siempre en cada etapa histórica como muestra de la capacidad de recuperación, resistencia, fortaleza y adaptación de su gente ante la presencia de fenómenos naturales. Cabe añadir que los trabajos sobre resiliencia empiezan a desarrollarse en psicología y psiquiatría desde la década de los 90 (BEcoÑa, 2006). Así, debido a que los conocimientos generados a este respecto son relativamente recientes, nos permitimos ejemplificar esta teoría en cada una de las etapas analizadas. 


\section{Adaptaciones socioambientales ante fenómenos meteorológicos y bélicos a lo largo de la historia de Matamoros, Tamaulipas. México}

\section{La problemática socio-ambiental y los fenómenos bélicos}

BoseruP (1984: 111) señala que los seres humanos preferían la caza y la recolección mientras pudiesen vivir de ellas. Sin embargo, aunque se tenían técnicas de domesticación de plantas y de animales, además de fertilización y de riego, las personas de ese entonces no adaptaron la agricultura y la ganadería más que a sus necesidades primarias, lo que provocó el desequilibrio entre la población y los recursos alimentarios. La agricultura fue una respuesta a una "crisis ecológica", causada por una nueva relación entre población y recursos desfavorables. ${ }^{1}$ El mundo urbano también facilitó la aparición de las guerras entre ciudades, las cuales incrementaban la demanda de armas y otros objetos metálicos para la protección de la incipiente población urbana, lo cual ocasionó además el desarrollo de medios de transporte terrestre y marítimo, con el consiguiente consumo de materiales. Teniendo en cuenta que la población mundial no alcanzó los 600.000 .000 de habitantes hasta finales del siglo XVII, la Tierra contaba entonces con amplísimas reservas de vida virgen o de biomas que conservaban gran parte de su biodiversidad original.

Más tarde, a mediados del siglo XVIII, con la Revolución Industrial que se inicia en Gran Bretaña y que se difunde luego por el resto de Europa y Norteamérica, comienza un proceso de innovaciones tecnológicas, productivas y sociales. Los progresos agrícolas y la industrialización redujeron la población agrícola y provocaron un éxodo rural paralelo al crecimiento de las ciudades y de los centros industriales, además de una nueva división del trabajo, aunado a un cambio en la estructura social. En este sentido, se reestructuraron los sectores productivos, los regímenes de propiedad y las clases sociales. El efecto ecológico de estos fenómenos en los países industrializados hizo que la inmensa mayoría de la población perdiera toda vinculación productiva y residencial con el medio rural, y pasara a satisfacer sus necesidades de vivienda y consumo alimenticio en un entorno muy artificializado.

Tras esta "Primera Revolución Industrial", caracterizada por el aprovechamiento del carbón mineral, el hierro y la máquina de vapor, tiene lugar una sucesión acelerada de adelantos científico-técnicos, entre los que cabe mencionar el desarrollo de la producción química, el aprovechamiento de la electricidad y del petróleo, con la enorme variedad de los productos de la industria petroquímica, paralelamente a la aparición de nuevos metales. Más adelante surge la llamada Revolución de la Información, con el descubrimiento de la energía nuclear y un desarrollo del amplio mundo de la electrónica y la radiodifusión, la
1. Cabe destacar el hecho de que la agricultura apareció con total independencia hace diez $o$ doce milenios cercana a las fuentes de agua de Egipto, Mesopotamia, China, India y Mesoamérica, debido a que son áreas caracterizadas por su clima fluctuante, su marcada estacionalidad, la presencia de masas importantes de animales herbívoros. 
televisión, la informática, las biotecnologías, todos cambios que han tenido como resultado una agravación sin precedentes de los impactos humanos sobre la biosfera. No obstante, los verdaderos problemas ambientales de esta crisis ecológica partieron de la segunda mitad de nuestro siglo XX, tras las dos guerras mundiales, al aparecer un nuevo orden mundial a nivel económico, político y demográfico.

Podemos señalar que aunque existía un interés sociológico por los temas medioambientales antes de los años 70, a partir de esta década se desarrollan trabajos de investigación de los sociólogos rurales sobre los recursos naturales (BuRch, 1972: 9) y de los sociólogos urbanos sobre los entornos construidos (Michelson, 1970: 324). La obra The Limits to Growth (MEADows, 1972) generó una preocupación por los impactos sociales de la escasez de recursos, ya que los gobiernos estaban centrándose más en el impacto de la escasez de energía que en las fuerzas sociales que influían en el uso de la energía. Dunlap \& MERTig (1992: 36) hablan de la renovada preocupación por los problemas medioambientales que en los Estados Unidos de América cobró aún más fuerza con la movilización de la opinión pública en el vigésimo aniversario del Día de la Tierra, el 22 de abril de 1990, un evento que despertó un compromiso público sin precedentes y que contribuyó a aumentar el número de miembros pertenecientes a organizaciones medioambientales.

MASKREY (1993: 6) alude que no es igual fenómeno natural que desastre natural. El primero es la representación del comportamiento interno de la naturaleza, y la categoría de peligroso se basa en su tipo o magnitud, más lo sorpresivo de su presencia. El segundo es la correlación entre fenómenos naturales peligrosos, tales como terremotos, huracanes o maremotos, entre otros, destacando ciertas condiciones socioeconómicas y físicas que conducen a la vulnerabilidad, entre ellas, el bajo ingreso económico, el género, la edad o el tipo de vivienda. Ligr (2005) menciona que el concepto de desastre natural se deriva como factor sociocultural que caracteriza los sistemas sociales y a sus comunidades, el cual puede ser medido cualitativamente en términos de la diferencia entre acciones sociales, políticas, económicas y ambientales que sirven para disminuir el riesgo mismo. Si bien es cierto que la globalización es un factor importante en la degradación del medio ambiente, podemos considerar también que ofrece oportunidades para caminar hacia el desarrollo sostenible del planeta facilitando la creación de políticas ambientales conjuntas entre países, buscando regular y solucionar la degradación ambiental, tal como se propone en el Tercer Informe del Club de Roma (Meadows, Randers, \& Meadows, 2004). 


\section{Adaptaciones socioambientales ante fenómenos meteorológicos y bélicos a lo largo de la historia de Matamoros, Tamaulipas. México}

La estabilidad entre el territorio y la población que lo habita requiere un proceso de prevención y de preparación comunitaria para hacer frente a los desafíos medio-ambientales, socio-económicos y políticos, en el cual los gobernantes deben ser competentes ante una gestión de crisis. Ante eventos inesperados, los gobiernos también deben promover el desarrollo de capacidades orientadas a consolidar los recursos materiales, económicos y humanos que permitan superar las adversidades. Holling (1973: 1) define la resiliencia dentro de un contexto ecológico, aunque él también señala que esta definición está ligada a los campos de estudio en que se emplea dicho concepto. Sin embargo, CutTer et ÁL. (2008: 2) definen la resiliencia comunitaria en el contexto de la gestión de desastres como la "habilidad de un sistema humano de responder y recuperarse. Incluye aquellas condiciones inherentes al sistema que le permiten absorber impactos y enfrentar el evento, así como los procesos adaptativos posteriores”. GodsснALK (2003: 136) señala que una ciudad resiliente es "una red sustentable de sistemas físicos y comunidades humanas”. OswaLd ET ÁL. (2013: 12) mencionan que los impactos del cambio climático han generado doble vulnerabilidad, la ambiental y la social, que llevaron a familias campesinas y comunidades enteras ante un dilema de supervivencia. Lo anterior implica generar mayormente la cultura de la prevención ante las posibles consecuencias de riesgos de pérdidas económicas y humanas asociadas a fenómenos naturales.

En lo referente a los conflictos bélicos, CLAusewitz (2002: 172) señala que la guerra es el elemento popular que permite llevar los conflictos sociales bajo la forma de nación. Según Holmes (2008: 538), la guerra es una experiencia universal que comparten todos los países y todas las culturas. En este trabajo destacamos las capacidades de reacción en la toma de conciencia de la población de Matamoros ante los embates de huracanes y guerras llegados por el mar y desde el norte del continente, por lo que es interesante conocer sobre los testimonios de adaptabilidad frente a estos desastres, aun antes de que los principios de sustentabilidad y de paz fueran parte de las agendas cotidianas. Además, nos valemos de recursos cartográficos disponibles sobre los temas en cuestión.

\section{Etapas históricas de las adaptaciones socioambientales} ante fenómenos meteorológicos y bélicos de Matamoros

Como ya mencionamos, el proceso de adaptación de la sociedad de Matamoros ante los embates hidrometeorológicos y armados lo dividimos en cinco etapas, delimitadas entre el nacimiento del poblado y la Guerra México-Estados Unidos, la segunda mitad del siglo XIX que coincide con la Intervención Francesa en México, el inicio del siglo XX, el desarrollo de 
2. Más tarde, en el año 1686, el capitán Alonso de León, "El Mozo", es comisionado para explorar hasta la desembocadura del río Bravo, y reporta que tal río es una vía navegable. En el año 1706, el capitán Juan José de Hinojosa llama a la zona "El Paraje de los Esteros Hermosos", sorprendido por la belleza de los numerosos esteros que caracterizan el lugar.

Figura 1.

Plano de 1772 que formó parte de la repartición de tierras de 1767 del Archivo

Municipal de Reynosa.

Se indica San Juan de los

Esteros.

Fuente: Dirección de Archivo Histórico de Matamoros, Tamaulipas, 2016 la industria maquiladora durante la segunda mitad del siglo XX, además de los retos a los que se enfrenta el municipio ante la violencia urbana producto del narcotráfico.

Matamoros, proceso de aprendizaje, adecuación y resistencia desde su colonización en el siglo XVI hasta su

\section{defensa territorial contra ejércitos estadounidenses en 1848}

En el año de 1519, una expedición realizada por el capitán Alonso Álvarez de Pineda nombra al ahora río Bravo como río de Las Palmas, además de hacer una descripción acerca de las tribus indígenas que habitaban la región que hoy conocemos como Matamoros. ${ }^{2}$ En 1747, don José de Escandón y el capitán Blas María de la Garza catalogan el lugar como poco adecuado para una futura fundación, debido a que la presencia de fenómenos naturales comenzaba a hacer estragos provocando frecuentes desbordamientos del río Bravo, causando serias inundaciones en la región y una gran problemática para sus habitantes. Dos años

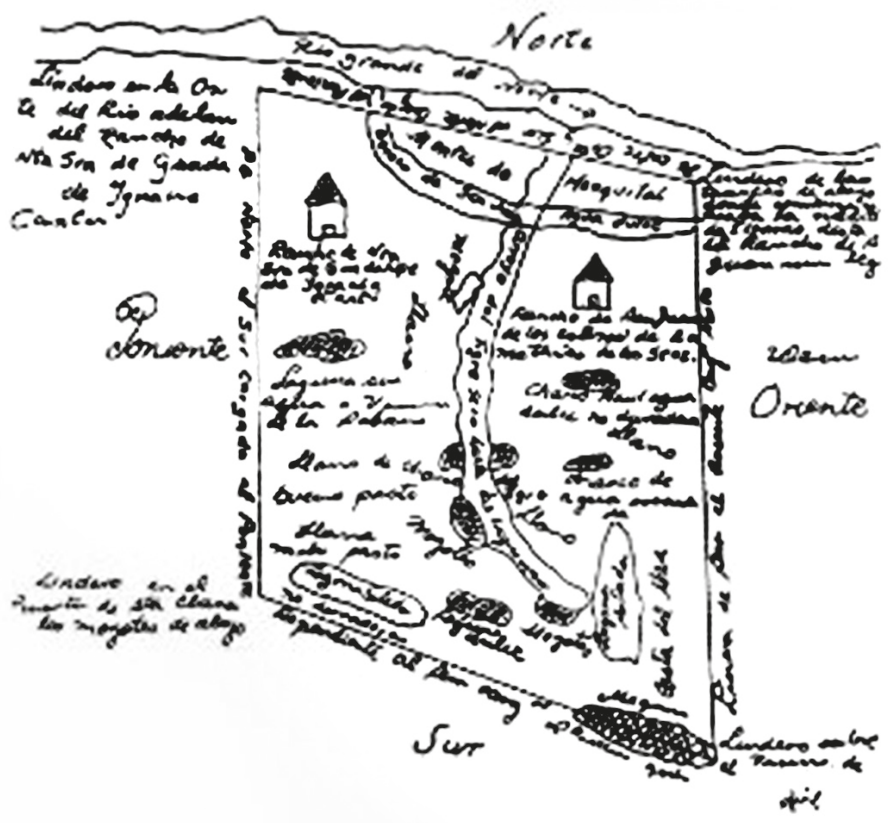

Cuaderno Urbano. Espacio, Cultura, Sociedad - Vol. 24 N. ${ }^{\circ} 24$ (Junio de 2018) pp. 047-072 - ISNN1666-6186 


\section{Adaptaciones socioambientales ante fenómenos meteorológicos y bélicos a lo largo de la historia de Matamoros, Tamaulipas. México}

más tarde, don Matías de los Santos Coy estableció en el espacio que actualmente ocupa la esquina nordeste de las calles Quinta y Matamoros un rancho ganadero llamado "San Juan de los Esteros Hermosos", el cual tuvo la necesidad de abandonar al poco tiempo debido a los frecuentes ataques de los indios que buscaban afanosamente oponerse al posicionamiento de sus tierras (figura 1 ).

En 1793, buscando evangelizar la provincia del Nuevo Santander, hoy Tamaulipas, llegaron al sitio los frailes franciscanos Francisco de Puelles y Manuel Julio de Silva, del Colegio Apostólico de Guadalupe Zacatecas, quienes establecieron una capilla en San Juan de los Esteros y propusieron un nuevo nombre para la comunidad. Pensando en la patrona de los misioneros, se bautizó como Congregación Nuestra Señora del Refugio de los Esteros. En el año 1814, la Villa del Refugio cambia su sitio original debido a las constantes lluvias e inundaciones, y comienza su nuevo trazo de ciudad a partir de la plaza principal, donde se consideró un lugar más alto para el poblamiento.

En el año 1836, durante la Revolución de Texas, Matamoros fue la fortaleza de muchos soldados mexicanos frente a los ataques rebeldes. Entre 1840 y 1844, la aduana de Matamoros no estaba situada en su respectivo puerto de mar, sino en sitios interiores cercanos a ellos. Desde la creación del puerto de El Refugio, en Matamoros, se había elaborado una serie de demandas con el objetivo de cambiar el sitio de desembarco de los navíos. Las disposiciones defendían el hecho de que el pueblo de Matamoros se había convertido en una importante ciudad con un flujo comercial que conectaba a varias regiones del norte de México. García (2007) menciona que el 4 de septiembre a las 22:00 horas de 1844, un huracán azotó la ciudad, varias construcciones sufrieron daños considerables, incluyendo el Palacio Municipal, aunado a que la población se veía involucrada en una tensión social de emergencia por los conflictos bélicos y naturales.

La invasión de los ejércitos estadounidenses a México fue la continuación de una política de expansión continental diseñada por los círculos gobernantes norteamericanos. La separación de Texas era alentada por intereses de terratenientes de los esclavistas sureños. La anexión texana al país del norte, en 1845, fue la medida que provocó la guerra contra México. Matamoros fue escenario de las dos primeras batallas del conflicto bélico entre los Estados Unidos y México. El pretexto fue la posesión de la franja comprendida entre el río Nueces y el río Bravo, territorio que desde la colonia era de la provincia del Nuevo Santander. 
A través del ahora territorio tamaulipeco, penetraron los invasores en territorio nacional, y ahí se libraron las primeras acciones bélicas.

En la batalla de Palo Alto del 9 de mayo 1846, se pone de manifiesto la superioridad de la artillería norteamericana al mando de Zachary Taylor, quien aprovechó la falta de un buen estratega militar en el bando opuesto, a pesar de que los soldados de línea y los oficiales mexicanos resistían con heroísmo. El 18 de mayo de ese año, Taylor ingresó en Matamoros. Debido al coraje demostrado por los pobladores en defensa de la ciudad, el mencionado general estadounidense respetó la permanencia de los representantes del ayuntamiento local, quienes solicitaron la protección de su población y el respeto a las garantías individuales. Taylor permitió que la autoridad municipal continuara administrando la justicia, lo que impidió los excesos de los invasores contra los civiles. Esta ocupación, que duró cerca de año y medio, permitió a Matamoros fungir como puerto libre para el comercio, lo que hizo que se experi-

Figura 2.

Plano de Matamoros y alrededores utilizado

por el capitán $M$. A.

Haynes y su regimiento

de caballería de

Tennessee, 30 de

noviembre de 1847.

Fuente: Dirección del

Archivo Histórico de Matamoros,

Tamaulipas, 2016

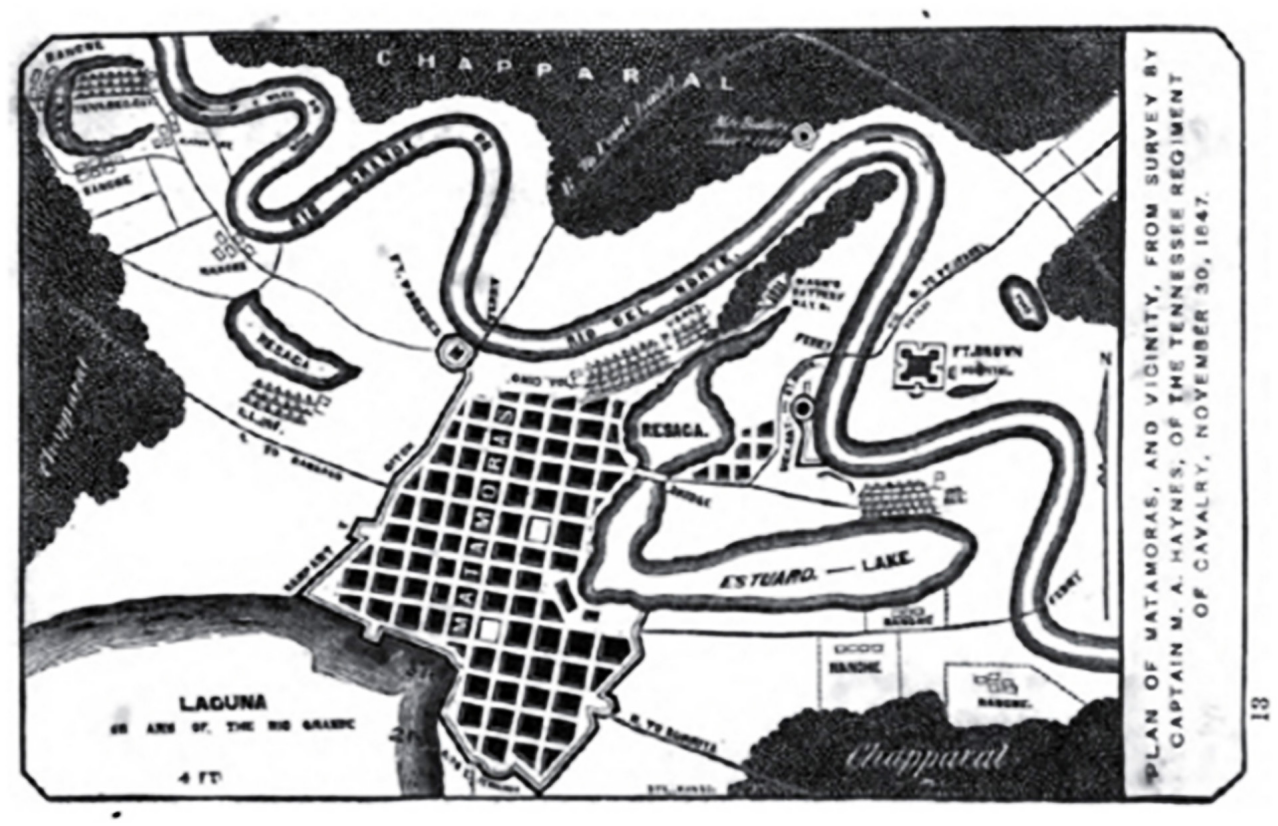


mentara una bonanza económica en plena guerra (Dirección del Archivo Histórico de Matamoros, 2016). Sin embargo, los intereses militares de los Estados Unidos estaban concentrados en la toma de la Ciudad de México, por lo que las tropas abandonaron Matamoros. El capitán M. A. Haynes, junto con su regimiento de caballería de Tennessee, utilizó un plano de Matamoros y sus alrededores para comenzar la salida el 30 de noviembre de 1847 (figura 2).

En febrero de 1848 es firmado el Tratado Guadalupe Hidalgo, documento en el que México reconocía la pérdida de casi 2,5 millones de $\mathrm{km}^{2}$. Desde la firma de este tratado, Matamoros se convertirá en una dinámica ciudad fronteriza, vecina de Brownsville, Texas. Aunque puede cuestionarse que se trate de un contexto de resiliencia, hacer frente a una situación de guerra y de pérdida de territorios permitió los pobladores de Matamoros transformar este escenario adverso en bonanza económica y de reconstrucción espacial, al verse beneficiados por una nueva frontera.

\section{Resistencia y capacidad como ciudad: regreso a condiciones} de relativa estabilidad desde mediados del siglo XIX ante embates bélicos europeos y fenómenos naturales en 1889

En el año 1851, la ciudad de Matamoros fue defendida contra los ataques de agresores que recientemente habían firmado el "Plan de la Loba", ya que las tropas de José María Carbajal eran apoyadas por soldados estadounidenses. Las tropas del general Francisco Ávalos, apoyadas por civiles al mando del presidente municipal Macedonio Capistrán, lograron rechazar al enemigo. Por esa victoria el Congreso del Estado de Tamaulipas otorgó a la ciudad los títulos de "Heroica" e "Invicta", que se sumaron al de "Leal", concedido por el gobierno federal en 1852.

La problemática socio-ambiental de este período en Matamoros se vio reflejada con una mayor presencia y fuerza de huracanes. No existía información cartográfica que permitiera a la población prevenir situaciones extremas. Los habitantes buscaban refugios de mayor protección ante los embates naturales. Además, ante la actividad bélica en Matamoros, la gente mostraba su capacidad para sobreponerse, por lo que la construcción del puerto marítimo de Bagdad representó un elemento para el impulso de la actividad comercial, aspecto que distinguió a Matamoros del resto de los municipios costeros del golfo de México. En el año 1858, el futuro de la ciudad cambió radicalmente después de que fue reconocida 
Figura 3. Plano del antiguo puerto de Bagdad en Matamoros, 30 de noviembre de 1847. Fuente: Dirección del

Archivo Histórico de Matamoros, Tamaulipas, 2016

como una región de comercio internacional o zona libre para esta actividad económica. Esta transformación trajo la urbanización, la industrialización y la expansión de la ciudad hacia el puerto Bagdad (figura 3).

Bagdad se convirtió en la puerta de importaciones y exportaciones entre Monterrey y los Estados Confederados de América durante la guerra civil estadounidense, ya que en 1861 el presidente Abraham Lincoln decretó el bloqueo de los puertos marítimos de la también llamada Confederación. Así, al tiempo que puertos como el de Nueva Orleáns estaban cerrados, los del nordeste mexicano, como Matamoros, y ciudades al sur del Bravo, como Nuevo Laredo, permitían el intercambio de dinero y de mercancías, tanto de manera legal como ilegal. Sin embargo, a pesar de que las entradas de los productos mencionados eran por el estado de Tamaulipas, en Monterrey, Nuevo León, se pagaban los derechos de aduana de la

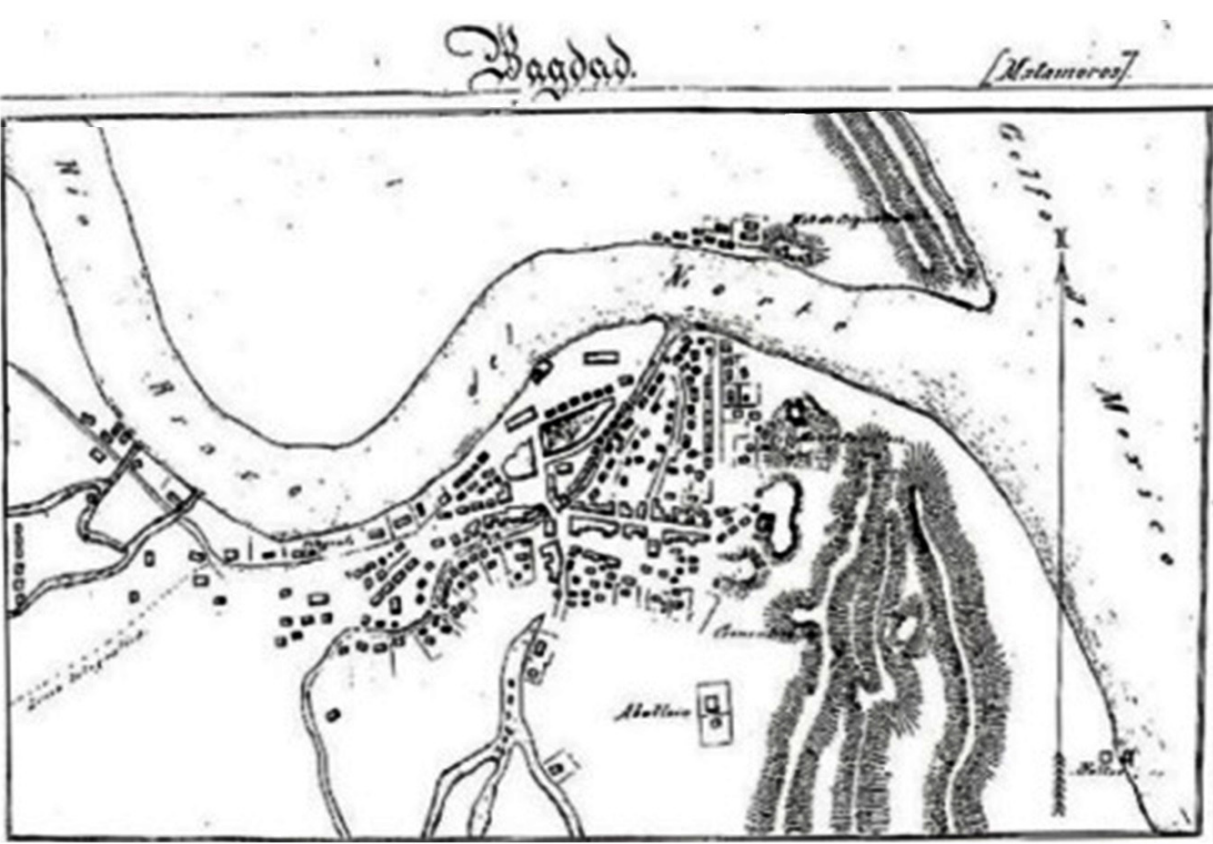




\section{Adaptaciones socioambientales ante fenómenos meteorológicos y bélicos a lo largo de la historia de Matamoros, Tamaulipas. México}

región (CERUTtI \& GonZÁLEZ, 1990: 223) hasta 1867. Este desarrollo también se debió a que el ferrocarril llegó a Matamoros, dado que es una zona fértil y propicia para la agricultura, lo cual permitía transportar granos al centro del país.

En 1861 se enfrentan grupos políticos locales por el control del puerto Bagdad y de su aduana. Estos grupos eran conocidos como los rojos, quienes eran partidarios del proyecto $n a-$ cionalista del presidente Benito Juárez, y los crinolinos, a favor del proyecto norestense de Santiago Vidaurri, gobernador en ese momento de Nuevo León. Posteriormente, en 1862, la soberanía nacional se vio amenazada por la intervención de fuerzas extranjeras de Francia. ZÁrate (2006: 67) destaca que en el estado de Tamaulipas hombres, mujeres, niños, jóvenes y ancianos ofrecieron su esfuerzo para combatir al intruso ejército francés haciendo respetar la integridad nacional.

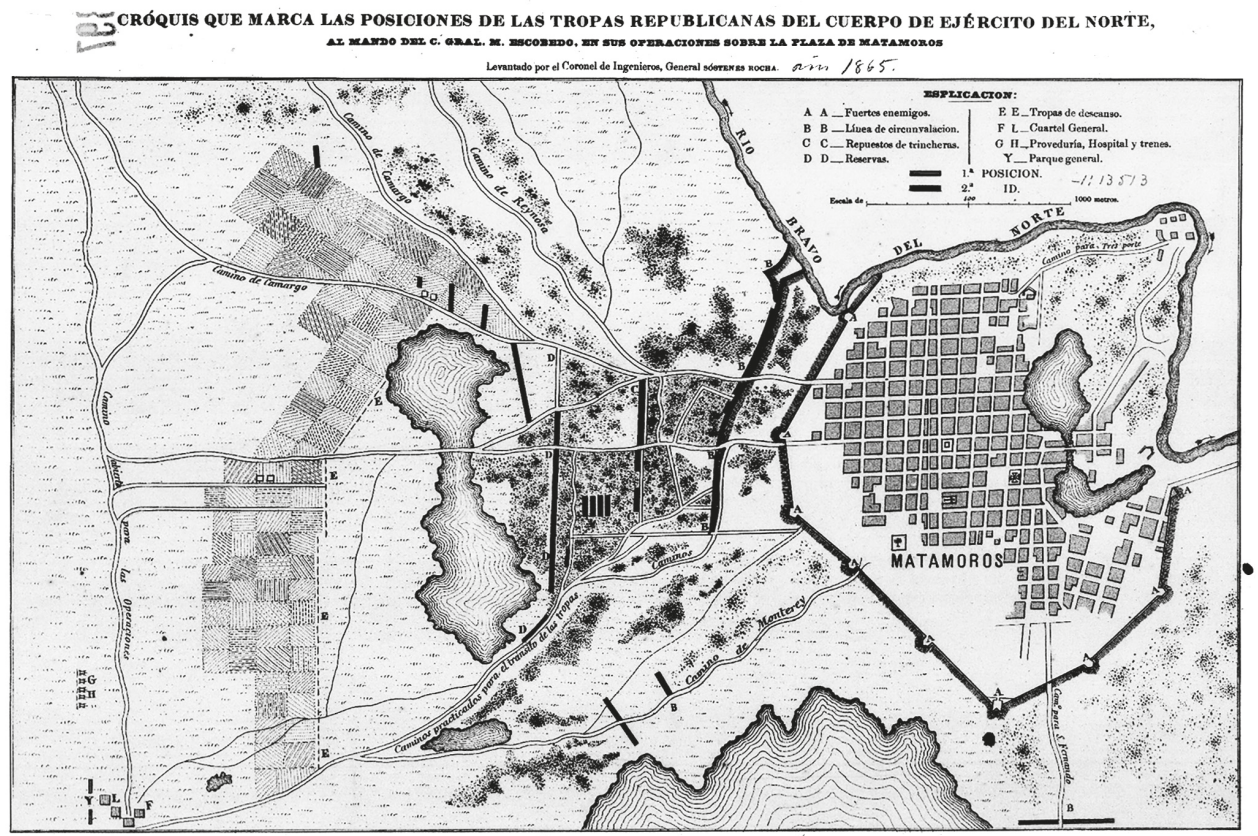

Cuaderno Urbano. Espacio, Cultura, Sociedad - Vol. 24 N. ${ }^{\circ} 24$ (Junio de 2018) pp. 047-072 - ISNN1666-6186
Figura 4.

Plano de las posiciones de las tropas

republicanas del cuerpo de Ejército del Norte al mando del general Mariano Escobedo en 1865. Fuente: Dirección del Archivo Histórico de Matamoros, Tamaulipas, 2016 
La batalla en Santa Gertrudis, del 16 de junio de 1866, al mando del general Mariano Escobedo, fue una victoria de vital importancia de las fuerzas republicanas contra el imperio mexicano de Maximiliano. La tropa conocida como el Ejército del Norte derrotó a una fuerza de cerca dos mil hombres, compuesta por soldados austriacos y conservadores mexicanos partidarios del imperio. Como resultado de esta victoria, el día 23 de junio se recuperaron Matamoros y Bagdad, lo que facilitó a las fuerzas nacionales la compra de armamento en la frontera con los Estados Unidos de América, además de provocar la retirada de tropas europeas hacia San Luis Potosí (figura 4).

En 1867, la finalización tanto de la guerra civil estadounidense como de la intervención francesa en México coincide con el momento cumbre del auge comercial del puerto fluvial de Matamoros y del vecino puerto marítimo de Bagdad, en el período conocido como "La Época de los Algodones". Sin embargo, durante las acciones bélicas, los ejércitos y el resto de la población eran impactados por fenómenos naturales, como el huracán de nombre Ferrocarril, ocurrido el 8 de octubre. Dicho huracán causó daños en gran parte de Matamoros, además de destruir el puerto Bagdad. En aquellos años no se conocía la intensidad de los "huracanes" ni existía un método de prevención para la población, por eso su nivel catastrófico era equiparado con los daños ocurridos en circunstancias bélicas. Así, la bonanza económica que se vislumbraba para esta zona fronteriza se vio interrumpida por el mencionado huracán. La población flotante, implicada sobre todo en las actividades aduanales y comerciales, se retiró. De las más de 20.000 personas que residían en Matamoros, solo cerca de 10.000 decidieron iniciar nuevamente la reconstrucción de la ciudad (RENDón, 1994). Aunado a que se empezaron a levantar edificaciones con materiales más resistentes, la solidaridad mexicana volteó hacia Matamoros y Brownsville, ya que por órdenes del gobierno federal salieron dos buques de Veracruz cargados con víveres, así como la inmediata respuesta de los estados de Nuevo León y Coahuila (Escobar, 2004).

En 1880, otro huracán abatió Matamoros, destruyó parcialmente la iglesia de la localidad y dejó sin hogar a más de 8000 personas. Nueve años después, en 1889, otro huracán arrastró con el puerto de Bagdad, lo que hizo suspender indefinidamente el servicio de barcos de cabotaje. La población de Matamoros se vio reducida a casi la mitad de su tamaño, lo que trajo otra terrible depresión económica a la ciudad. Sin duda, la etapa de posguerra vislumbraba un desarrollo de la dinámica socio-económica de la ciudad gracias sus grandes 


\section{Adaptaciones socioambientales ante fenómenos meteorológicos y bélicos a lo largo de la historia de Matamoros, Tamaulipas. México}

flujos comerciales. La mayor actividad comercial en la región sobre el río Bravo se daba en comunidades ribereñas desde Nuevo Laredo hasta Matamoros.

Siguiendo a Aguiar \& Acle-Tomasini (2012: 55), podemos señalar que "la resiliencia se trata de un proceso interactivo entre las personas y su medio cuando se está frente a una situación de riesgo". Este proceso es más evidente conforme se tengan mejores recursos para hacerle frente a una adversidad. Los autores hacen alusión a los macrosistemas, como aquellos patrones institucionales de la cultura o subcultura que en el caso de este trabajo corresponden a sistemas económicos, sociales y políticos que sirven como soportes de información e ideología que tanto explícita como implícitamente dotan de significado y motivación a las redes sociales que existían dentro de Matamoros y como parte de una estructura de soporte nacional.

La adaptabilidad de Matamoros en los albores del siglo XX:

el crecimiento al cambio inesperado de su población y territorio, habilidades para recuperarse de adversidades a partir de 1929

\section{y la segunda época de oro del algodón}

En 1910, México vivía la paz porfiriana asentada en la desigualdad, la cual dio origen desde los primeros años del siglo XX a huelgas y rebeliones por todo el país contra una dudosa posesión de la tierra en manos de un grupo privilegiado, sumado a las excesivas concesiones que se daban al capital extranjero. El terreno era más que fértil para la gestación del movimiento armado conocido como Revolución Mexicana. El presidente de la nación, general Porfirio Díaz, declaraba en una entrevista que estaba dispuesto a dejar el gobierno y a formar elecciones creíbles (TURNER, 2015: 76), lo que representa para Francisco I. Madero y su Plan de San Luis el inicio de las hostilidades revolucionarias, secundado por Francisco Villa en el norte del país y por Emiliano Zapata en el sur. En Tamaulipas, Alberto Carrera Torres en mayo de 1911 se incorporaba a la lucha armada en pro del agrarismo, y Matías Guerra llegaba a la gubernatura, mientras que se reorganizaba el Partido Liberal a nivel nacional. El asesinato del ya entonces presidente Francisco I. Madero genera en Tamaulipas sucesos en favor de reformar la Constitución. Así, las fuerzas revolucionarias toman Matamoros por su importancia estratégica en junio de $1913 .^{3}$

En 1913, los ejércitos revolucionarios llegan a Matamoros, lugar donde se realiza el primer reparto agrario en el país. Al año siguiente, las propiedades de varias haciendas son cedidas a los campesinos en la ciudad de Matamoros. El general Luis Caballero se convierte en
3. En Matamoros se concentraba el general Pablo González, como jefe de la División del Noreste, quien posteriormente realiza la toma de Ciudad Victoria. 
gobernador y comandante militar, quien entre sus primeras tareas encomienda la creación de comisiones agrarias, las cuales se dan a la tarea de revisar títulos de propiedad, fomentar la irrigación y proteger la pequeña propiedad. Para el año 1915, la ciudad de Matamoros es lugar de escaramuzas entre ejércitos revolucionarios, ya que fuerzas villistas son repelidas por tropas constitucionalistas.

Posteriormente a la Revolución Mexicana, en paralelo con la crisis económica de 1929 en los Estados Unidos de América, en Matamoros se inician los primeros trabajos de planeación urbana, en los que la comunidad expresa el deseo de modernizar su ciudad. Los cambios políticos no estuvieron aislados de los impactos causados por los fenómenos naturales. El 1933, once huracanes golpearon el litoral costero del golfo de México en el área comprendida entre Tampico, en Tamaulipas, y Corpus Christi, Texas. Destaca el meteoro llamado Cuba-Brownsville de categoría 5, el cual devastó Matamoros (SMN, 2010) destrozando, entre otras cosas, las torres de la iglesia catedral. Los daños fueron tan grandes que el recién llegado a la presidencia de la República, general Lázaro Cárdenas, comisionó al Gobierno Municipal de Matamoros la tarea de restablecer la economía en la ciudad, e implementó la construcción del distrito de riego para generar empleos entre la población. Como consecuencia, el distrito de riego de Matamoros es, hasta el momento de la presente redacción, el más grande de la República Mexicana.

Otro efecto positivo de la llegada continua de huracanes se da en 1935, cuando bajo la administración del Ing. Eduardo Chávez se construyen los bordos de defensa de la ciudad, contra las inundaciones ocasionadas por el desbordamiento del río Bravo. Cinco años después, inicia operaciones el distrito de riego del Valle Bajo del río Bravo, el cual comprende parte de los municipios de Matamoros, Valle Hermoso, Río Bravo y Reynosa. En este sentido, los impactos meteorológicos hacían de las tierras rurales de Matamoros el lugar idóneo para el renacer del cultivo del algodón. En esta nueva etapa, que inicia en 1936, esta riqueza agrícola alcanza su clímax durante la Segunda Guerra Mundial, momento en que los productos mexicanos tienen gran demanda en Europa y Estados Unidos (Aguilar, 1999).

CANSEco (2001: 317) destaca que una tercera y última época de oro del algodón en la región de Matamoros se inició casi en la década de los 50 del siglo XX, gracias al impulso agrícola regional. Así, se van creando asentamientos humanos fuera de las murallas que sirvieron para la defensa militar de Matamoros. Por ejemplo, en 1948, surge la colonia Casa Colorada, 


\section{Adaptaciones socioambientales ante fenómenos meteorológicos y bélicos a lo largo de la historia de Matamoros, Tamaulipas. México}

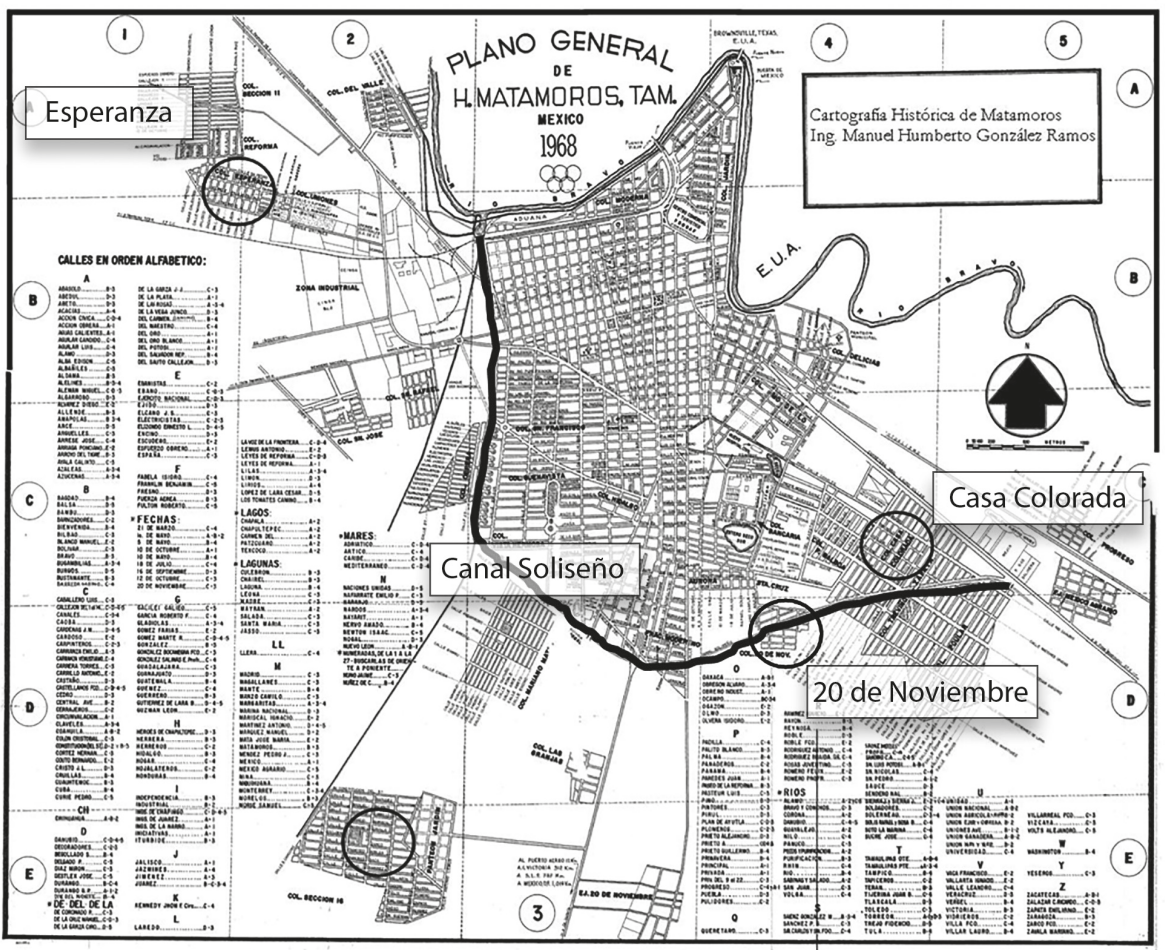

Figura 5.

Expansión periférica de Matamoros fuera de los límites de la línea imaginaria de la localización de los fortines del siglo XIX, en 1968. Fuente: Dirección del Archivo Histórico de Matamoros, Tamaulipas, 2016

mientras que las colonias Treviño Zapata y Popular nacen en 1957. Como parte de este fenómeno, en 1968, nace la colonia El Milagro o 20 de Noviembre en tierras ejidales (figura 5).

En este período emergen nuevas condiciones económicas y espaciales para la ciudad fronteriza en cuestión. Podemos señalar que la población intramuros de Matamoros ya había desarrollado estrategias para salir adelante tanto de eventos bélicos como hidrometeorológicos. Incluso, ante la adversidad que representaba el impacto de un huracán, seguía una etapa de progreso agrícola, como en el caso del algodón. Sin embargo, el crecimiento económico provocó la creación de barrios fuera de las murallas protectoras de la ciudad. Autores como BEcoÑa (2006: 143) 
señalan que la resiliencia debe de verse como un proceso y merece un análisis multifactorial, ya que "al incrementarse la interacción entre diversos factores de riesgo, se incrementan más los mismos”, pudiendo llegar a ser exponencial el efecto de los múltiples factores de riesgo.

\section{La evolución de Matamoros, fenómenos meteorológicos recientes}

y su transición a la industria maquiladora de 1948 a 1988

A mediados del siglo XX el triunfo de la burguesía parecía universal. La progresiva ampliación de los derechos democráticos y la supresión de los antiguos privilegios de casta parecían señalar el camino de un mundo más libre. La nueva clase social que había irrumpido en escena con la industrialización, el proletariado, elaboraba proyectos alternativos a los de esta sociedad autosatisfecha. La posguerra dejaba sentir importantes cambios en la estructura urbana. Las distintas clases sociales dejaron de vivir en el mismo espacio, abandonaron el centro y ocuparon las periferias. Las clases sociales medias y altas que aspiraban al modo de vida estadounidense en suburbio se mudaron a nuevos barrios, planificados y dotados de servicios. El centro urbano degradado y la periferia ocupada ilegalmente quedaron para los trabajadores y la población marginal. Como parte de este fenómeno, varios poblados rurales también fueron absorbidos por las manchas urbanas.

Alvarado (1993) menciona que durante casi toda la década de los 50 Matamoros cobijó la transición entre un mercado de trabajo fundamentalmente rural, en el que predominaba la fuerza de trabajo masculina, con la aparición paulatina de un mercado de trabajo urbano industrial, en el que predomina la presencia de mano de obra femenina, al menos en sus primeras etapas. En 1960, se instaló en Matamoros la primera maquiladora de la República, la Nielsen de México, mucho antes de que se autorizara este programa en toda la frontera (Romero \& Calvario, 1990).

La aparición de las maquiladoras como empresas importadoras de productos con materia prima local, exentos de pagos arancelarios, constituyó una alternativa para el desempleo ocasionado por la caída de la agricultura y una oportunidad para los trabajadores mexicanos que regresaban de Estados Unidos al terminar el llamado "Programa Bracero". Dicho programa constituyó un acuerdo laboral temporal iniciado en agosto de 1942, debido a un intercambio de notas diplomáticas entre Estados Unidos y México, dentro del marco de la Segunda Guerra Mundial. Así, la transición en el mercado laboral, el crecimiento del 


\section{Adaptaciones socioambientales ante fenómenos meteorológicos y bélicos a lo largo de la historia de Matamoros, Tamaulipas. México}

empleo femenino y el desplazamiento del sector agrario se explican por la acción simultánea de factores demográficos y ajustes en las dinámicas familiares, que permitieron una doble transformación del trabajo de campo masculino al empleo en la ciudad con mano de obra femenina. Entre estos factores deben considerarse el papel de la organización sindical de los trabajadores, como mediador de la transición a un mercado de trabajo urbano industrial (ZÁrate, 1995). Más tarde, el 9 de octubre de 1966, arribó el huracán Inés a las costas tamaulipecas. Este fenómeno se esperaba que golpeara con fuerza a la ciudad de Matamoros, pero en el último momento cambió su trayectoria y entró por la costa de Tampico.

Uno de los huracanes más famosos por su gran impacto y magnitud de fuerza desmedida fue el llamado Beulah, que azotó el Estado de Tamaulipas el 9 de septiembre de 1967, con una intensidad de categoría 4 en la escala de Saffir-Simpson, y dejó cientos de miles de damnificados en las ciudades de Matamoros, Reynosa, Camargo y Nuevo Guerrero. Se calculó en un millón y medio la cifra de damnificados, casi la mitad de la población del estado de ese año, la cual era cercana a los tres millones. El gobierno municipal a cargo del Ing. Enrique Siller Flores tomó medidas pertinentes antes y después de la llegada del huracán. Primero, un comité inició con el desplazamiento a lugares seguros de aquellos habitantes que vivían en construcciones endebles. Posteriormente al evento, se gestionó ante los gobiernos estatal y federal la ayuda para la reconstrucción de Matamoros (CANSECO, 2001). Cabe agregar que con la finalidad de reactivar económicamente este puerto fronterizo, en noviembre de ese año empezaron a operar los vuelos comerciales entre la ciudad de México y Matamoros.

En 1970, a pesar de que aún quedaban vestigios de la bonanza y auge comercial del oro blanco, como se lo conocía al algodón, en Matamoros surge un nuevo tipo de conflicto bélico, que ya no provenía de fuerzas invasoras o de una guerra civil: el de la disputa por la posesión de las tierras destinadas a este cultivo. Aunque podríamos cuestionar si se trata de una acción resiliente, la población integró en la memoria colectiva y en el dominio popular estas luchas en varios cantos y música regional, llamados corridos, como el caso de la familia Fierro del Rancho La Piedra. En estas narraciones señala que catorce de los miembros de esta fueron abatidos a balazos por querer arrebatarles sus tierras (Siglo XX, 2013). Cabe agregar que existen trabajos como el de Boschán (2004) que hablan de la resiliencia como componente de la construcción de la memoria colectiva. 
4. Inesperadamente, Gilberto desvió su trayectoria en dirección de Monterrey, lugar donde se pensó que todo el mundo estaría a salvo. Las consecuencias fueron tremendas, ya que hubo más muertes y destrozos en Monterrey y su zona conurbada que en el estado completo de Tamaulipas.

El huracán Gilberto es recordado como uno de los eventos más destructores surgidos en el océano Atlántico, ya que su presencia en el mar Caribe

$y$ en el golfo de México

le valió ser conocido en México como "el huracán del siglo XX”. El fenómeno que presentó vientos máximos de 296 kilómetros por hora es el tercero que registra la historia mexicana por la intensidad de sus vientos y las lluvias torrenciales que asolaron comunidades enteras en

los estados de Quintana Roo, Yucatán, Tamaulipas y Nuevo León.
Cerca del final de la década, aparecerían nuevos casos de violencia urbana, como en 1978, cuando se desata una serie de disturbios, producto de protestas estudiantiles, después de que un joven fue muerto a golpes por fuerzas policíacas. El Palacio Municipal fue incendiado, varios comercios saqueados y quemados, lo que obligó a la intervención de las fuerzas militares. CANSECO (2001) señala que entre los logros de esos movimientos se estableció un plan director urbano, el cual buscaba mejorar las condiciones generales de la población.

La década de los 80 del siglo XX quedó marcada por dos de los eventos meteorológicos más devastadores que impactaron en el nordeste mexicano. El 9 de agosto de 1980, autoridades de protección civil y militares ayudaban a la población de Matamoros a prepararse contra el huracán Allen, uno de los más violentos que han impactado el mar Caribe y el golfo de México. Con vientos de más de $300 \mathrm{~km} / \mathrm{h}$, el meteoro obligó a desalojar de sus hogares a más de 25.000 personas (León \& GraizBord, 2009). Cabe mencionar que, a pesar de los estragos que provocó el huracán en la ciudad, la recuperación fue relativamente rápida gracias al apoyo proveniente del interior del país. En lo local, el restablecimiento de la electricidad y del suministro de agua potable fueron relativamente rápidos (CANSECo, 2001).

Más tarde, el 17 de septiembre de 1988, entró el huracán Gilberto por el vecino Municipio de San Fernando, causando confusión entre los pobladores y caos vehicular, pues pensando que el meteoro impactaría Matamoros, en el sitio se establecieron barricadas para contener los daños, además de brigadas de ayuda. En el dominio público se mencionaba que varios de los residentes de esta ciudad, considerando la fuerza y la trayectoria que traía el huracán, decidieron refugiarse en el área metropolitana de Monterrey, donde sí hubo grandes daños ${ }^{4}$.

TRUjILLO (2006) señala que se deben impulsar acciones para favorecer la inclusión social de la resiliencia, para que se aproveche la vitalidad, la capacidad y la energía para participar activamente en el presente y construir con el apoyo un proyecto de vida. La autora hace referencia al huracán Katrina en Nueva Orleans, en 2005, el cual impactó a personas de diferentes culturas. En este sentido, las comunidades que están expuesta s a este tipo de eventos, como Matamoros, particularmente en el período que acabamos de mencionar ante el huracán Beulah, desarrollan conexiones que van desde la familia y las amistades cercanas, hasta las institucionales. 


\section{Adaptaciones socioambientales ante fenómenos meteorológicos y bélicos a lo largo de la historia de Matamoros, Tamaulipas. México}

\section{Matamoros frente a retos de planeación y la violencia urbana} de 1990 hasta la segunda década del siglo XXI

El crecimiento urbano de Matamoros durante los primeros años del nuevo milenio se dio básicamente hacia el poniente, rumbo a la ciudad de Reynosa, y hacia el sur, en dirección de Ciudad Victoria, capital de Tamaulipas. De alguna manera, la expansión hacia el norte ha sido limitada por el río Bravo, con su función de frontera internacional. Sin embargo, existe una conurbación espacial y funcional en las ciudades de Matamoros y Brownsville. Por otra parte, el crecimiento rumbo al poniente se vio limitado debido a que en esa zona coinciden las tierras bajas del río y las del litoral marino, aunque sí existen asentamientos con personas que viven en condiciones que pueden considerarse normalmente precarias (figura 6).

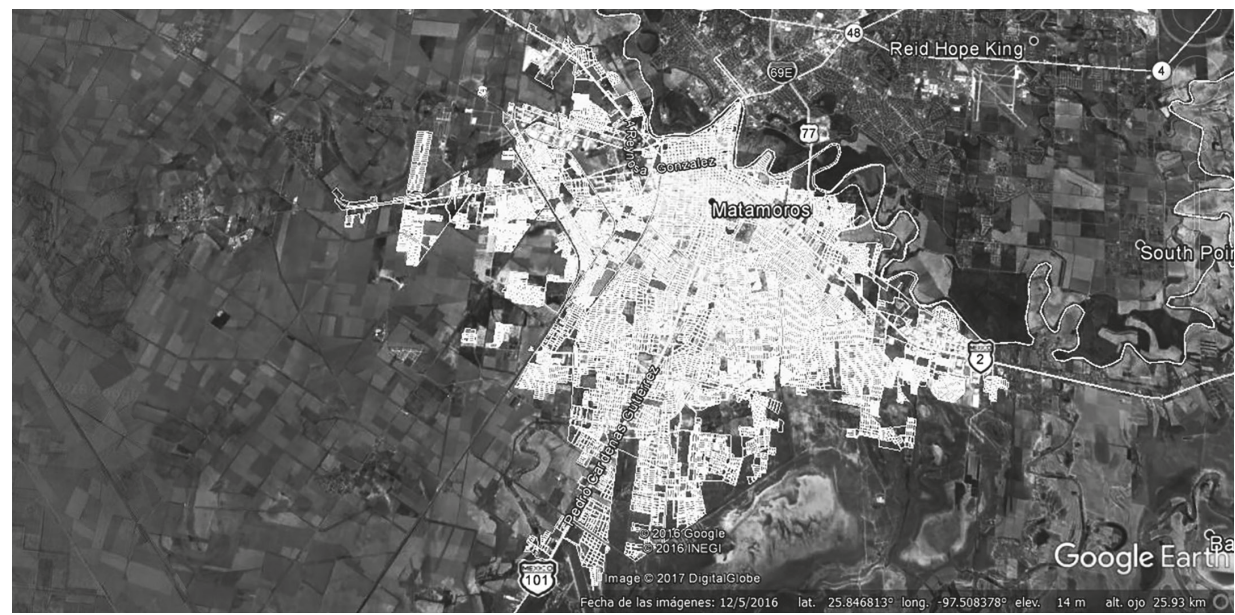

En la segunda década del siglo XXI, los problemas que sufre el medio ambiente son alarmantes, más tomando en cuenta la velocidad con que se deteriora el planeta Tierra. El cambio climático, la superproducción de residuos, la desertificación, el deterioro de la capa de ozono, las diferencias entre el norte/sur, el aumento del índice de pobreza, además de la contaminación de agua, aire y suelo son aspectos que se deben afrontar y que en el siglo XXI han pasado a formar parte no solo de las instituciones, sino también a los ciudadanos particulares.
Figura 6.

Mancha Urbana de Matamoros, Tamaulipas, en 2010. Fuentes:

Dirección del Archivo Histórico de Matamoros, Tamaulipas. 2016; INEGI, 2013, Google Earth, 2017. Editado por los autores 
5. Cabe recordar que los huracanes reciben su nombre por una convención alfabética, y su intensidad está en función de cuando sobrepasan una velocidad de viento superior a las 73 mph o 117 kph y obtienen forma de espiral, con un ojo en el centro, comúnmente llamado "el ojo del huracán”.

\section{Al analizar la exposición} de bienes y personas, así como la vulnerabilidad de la población, se consideran

factores tales como los daños económicos, la complejidad y la naturaleza del riesgo, y aspectos socioeconómicos y políticos de la población afectada.

7. Agradecemos sinceramente la participación de todos los involucrados en la elaboración de este trabajo, señalando que la información recabada en la Dirección del Archivo

Histórico de Matamoros en 2016 fue fundamental para hacer referencia a los hechos pasados, sobre todo en cuanto a las épocas en que se desconocía cómo convivir por completo con estos fenómenos meteorológicos y sus consecuencias.
En 2010, el municipio de Matamoros se vio afectado por los huracanes Alex, Hermine y Karl, cuyas intensas precipitaciones pluviales afectaron tanto a la población urbana como a la rural. Centenas de colonias se declararon como zona de siniestro por parte del gobierno federal; sin embargo, la atención fue relativamente rápida, entre otras cosas gracias a los adelantos tecnológicos. Es decir, los huracanes se detectan por satélite y por radares meteorológicos prácticamente desde que comienzan a formarse, por lo que generalmente hay una advertencia de entre tres o cuatro días anteriores a la llegada de una tormenta tropical. Así, conociendo los desplazamientos y la fuerza del huracán, se puede prevenir la pérdida de vidas humanas (SMN, 2010) . Como hemos visto, los impactos sociales y económicos de un fenómeno meteorológico en Matamoros dependen de la exposición de personas o bienes, así como de la vulnerabilidad de la población ${ }^{6}$. La figura 7 muestra las trayectorias de los principales huracanes que impactaron en la costa tamaulipeca desde 1967 hasta 2010.

Aunque podemos señalar que de alguna manera los habitantes de Matamoros aprendieron a lidiar con los fenómenos hidrometeorológicos, el riesgo ahora está en las luchas entre bandas de narcotraficantes por el control de la plaza. Por ejemplo, en 2015, una granada explotó en las instalaciones de la empresa Televisa, y el directivo del diario El Mañana fue golpeado, además de que súbitamente se registraron balaceras en las calles. Escuchar nombres como "El Cártel del Golfo" o "Los Zetas”, aunado a la presencia de fuerzas militares en la vía pública es un miedo latente en la ciudad (FLores, 2016). En este sentido, recluirse en la vivienda, evitar los sitios donde se enfrentan o posiblemente se enfrentarán los grupos delictivos, así como cruzar a Brownsville o emigrar distan mucho de ser estrategias resilientes. ${ }^{7}$

\section{Conclusiones}

Durante este trabajo hemos considerado a Matamoros como una ciudad donde los procesos de adecuación pueden ser concebidos como elementos que integran el concepto de resiliencia. En respuesta a las interrogantes planteadas en este trabajo, podemos señalar que las características de los embates meteorológicos y bélicos que impactaron en la zona de Matamoros han estado en función del tipo de evento. Es decir, en el caso de los huracanes ha dependido de los rasgos propios del meteoro, tales como la trayectoria y la intensidad, mientras que en el caso de luchas se ha reaccionado ante invasiones extranjeras, guerras civiles y guerrilla urbana. Podemos señalar que los habitantes se comportaron dentro del contexto propio de cada evento, desarrollando estrategias de prevención, enfrentamiento y recuperación. 


\section{Adaptaciones socioambientales ante fenómenos meteorológicos y bélicos a lo largo de la historia de Matamoros, Tamaulipas. México}

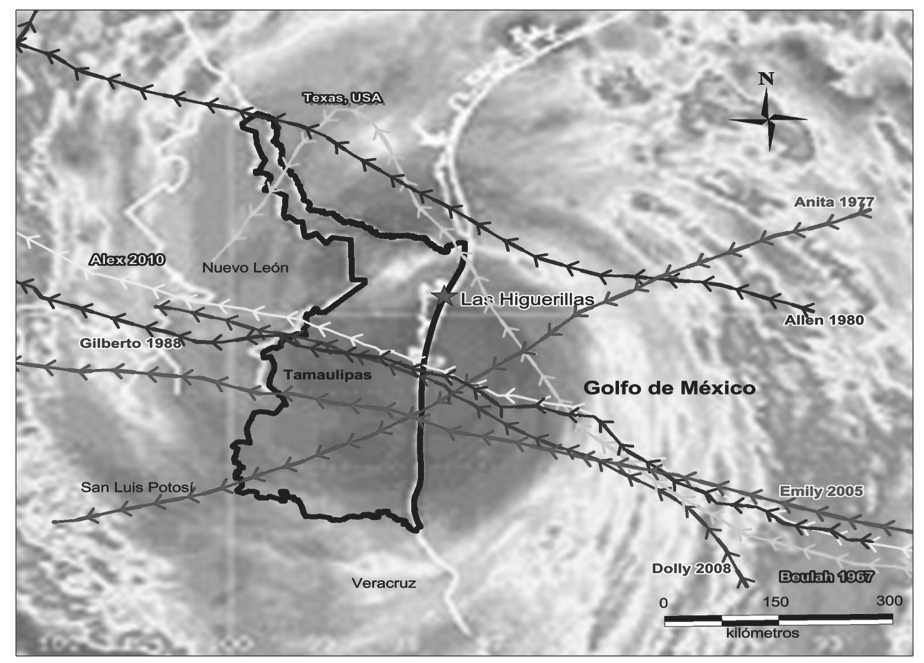

Por otra parte, la resiliencia desde el punto de vista del desarrollo se puede comprender como un proceso y no como un resultado, debido a que - como hemos mencionado-la comunidad tiene como estrategia de recuperación aprovechar y desarrollar conexiones que van desde la familia y las amistades cercanas hasta las institucionales, incluso integrándolas en la memoria colectiva. Cartográficamente podemos apreciar que tanto las fortificaciones como la búsqueda de áreas seguras, así como las conexiones hacia ciudades como Reynosa y Ciudad Victoria, además de la que se tiene con los Estados Unidos y el Puerto de Bagdad, permitieron estructurar la traza urbana. En este sentido, las zonas más sensibles de ser inundadas se presentan hacia el oriente, es decir, rumbo a la costa del golfo de México, donde se localiza el citado puerto y donde tiende a ubicarse la población socialmente más desfavorecida.

Por tanto, a lo largo de este texto pudimos conocer cómo la población tanto urbana como rural de la zona costera de Matamoros, Tamaulipas, ha mostrado estrategias de resiliencia, al buscar adaptarse a las situaciones adversas producto de desastres tanto naturales como antrópicos. Nuestra reseña muestra que no es fácil vivir este tipo de experiencias, sobre todo si se presentan de manera materialmente simultánea. Además, en los albores del siglo XXI, por la situación imperante de inseguridad que se vive en el país, se suma la violencia urbana que se traduce
Figura 7.

Trayectorias de los principales huracanes que impactaron en la costa tamaulipeca desde 1967 hasta 2010. Fuente: elaboración propia, con información de la Dirección del Archivo Histórico de Matamoros, Tamaulipas, 2016 
en la guerra de las narco-bandas en Matamoros. A lo largo de la historia de esta ciudad, las personas han luchado por proteger la que en el siglo XIX era una joven nación mexicana. En una etapa de madurez, las personas combatieron por una repartición justa y equitativa de tierras para los campesinos. Sin embargo, la violencia de hoy no necesita la participación del ciudadano común. El matamorense de hoy no puede dejar su sangre en las calles.

\section{Bibliografía}

AGUIAR, Enrique \& ACLE-TOMASINI, Guadalupe (2012). "Resiliencia, factores de riesgo y protección en adolescentes mayas de Yucatán: elementos para favorecer la adaptación escolar”. En Acta Colombiana de Psicología, Universidad Católica de Colombia, Bogotá.

AGUILAR, Adrián (1999). "México City Growth and Regional Dispersal: the Expansion of Largest Cities and Spatial Forms”. Habitat International, Vol. 23, núm. 3.

ALVARADO, Arturo (1993). "Trabajo y organización gremial en Matamoros”. En Estudios Sociológicos XI: 33, 1993.

BECOÑA, Elisardo (2006). "La resiliencia en la psicología social”. En Revista de Psicopatología y Psicología Clínica Vol. 11 núm. 3. Asociación Española de Psicología Clínica y Psicopatología, Valencia. http://aepcp.net/arc/01.2006(3).Becona.pdf consultado el 21 de octubre de 2013.

Boschán, Pedro (2004). "Dolor, Trauma y Resiliencia: La Construcción de la Memoria Colectiva”. En Artículos sobre Ferenczi. Clínicos trauma-abuso. Asociación Latinoamericana Sandor Ferenczi, Santiago de Chile. http://www.alsf-chile.org/Indepsi/Articulos/Trauma-Abuso/Dolor-Trauma-y-Resiliencia-La-Construccion-de-la-Memoria-Colectiva.pdf.

BOSERUP, Ester (1984) Evolución Social. Madrid. Ediciones AKAL.

BURCH, William (1972) El nuevo paradigma ecológico en sociología del ambiente. Bélgica. Université Libre de Bruxelles, Bélgica.

CANSECO, José (2001) Historia de Matamoros. Gobierno Municipal, Matamoros, Tamaulipas. CERUTTI, Mario \& GONZÁLEZ, Miguel (1990). "Guerra y comercio en torno al río Bravo (1855-1867). Línea fronteriza, espacio económico común”. En Historia Mexicana, vol. 40, núm. 2, México, El Colegio de México. En línea: http://historiamexicana.colmex.mx/index. php/RHM/article/view/2164/3008.

CUTTER, Susan; BARNES, Lindsey; BERRY, Melissa; BURTON, Christopher; EVANS, Elijah; TATE, Erick \& WEBB, Jennifer (2008). "Community and regional resilience: Perspectives from hazards, disasters and emergency management”. CARRI Research Report 1. Oak Ridge, Tennessee: Community \& Regional Resilience Initiative. En http://www.resilientus. org/library/FINAL_CUTTER_9-25-08_1223482309.pdf.

FLORES, Raúl (2016). “Operan para cárteles 45 grupos armados”. En Excélsior, Mé- 
xico, http://www.excelsior.com.mx/nacional/2016/04/10/1085638 consultado el 7 de febrero de 2017.

CLAUSEWITZ, Karl (2002) De la guerra. México, Editorial Librodot.com. http://www. librodot.com.

CONAPO (2012) Sistema Urbano Nacional. México, Consejo Nacional de Población. http:// www.conapo.gob.mx/en/CONAPO/Catalogo_Sistema_Urbano_Nacional_2012.

DELGADO, Gregorio (2010). "Conceptos y metodología de la investigación histórica”. En: Revista Cubana de Salud Pública. Sociedad Cubana de Administración de Salud, La Habana. http://www.redalyc.org/articulo.oa?id=21416134003.

DIRECCIÓN DEL ARCHIVO HISTÓRICO DE MATAMOROS (2016) Mapoteca, Matamoros, Gobierno Municipal de Matamoros.

DUNLAP, Riley, \& MERTING, Angela (1992). "American environmentalism: The U.S. environmental movement”. 1970-1990, Washington, D. C.: Taylor and Francis.

ESCOBAR, Antonio (2004) Desastres agrícolas en México: catálogo histórico, tomo II, siglo XIX (1822-1900). Fondo de Cultura Económica, México.

GARCÍA, Santos (2007). "Historiador recuerda los huracanes más destructivos". Brownsville, El Nuevo Heraldo: La Voz del Valle. http://www.elnuevoheraldo.com/el_valle/historiador-recuerda-los-huracanes-m-s-destructivos/article_381d1c38-b265-5ba8-9873-b15039fb795e.html consultado el 7 de febrero de 2017.

GODSCHALK, David (2003). "Urban Hazard Mitigation: Creating Resilient Cities”. Natural Hazards Review 4.

GOOGLE EARTH (2017) Image Landsat: Data SIO, NOAA, U.S. Navy, NGA, GEBCO, Mountain View, Google Inc. https://www.google.com/earth/ consultado el 19 de abril de 2017.

HOLMES, Richard (2008) Un mundo en guerra: Historia Oral de la Segunda Guerra Mundial. Editorial Crítica, Barcelona, España.

HOLLING, Crawford (1973). "Resilience and stability of ecological systems". Annu. Rev. Ecol. Syst. 4.

INEGI (2013) Censos y conteos de población y vivienda. Aguascalientes: Instituto Nacional de Estadística, Geografía e Informática. http://www.inegi.org.mx/est/contenidos/Proyectos/ ccpv/default.aspx consultado el 29 de diciembre de 2016.

LEÓN, Cuauhtémoc \& GRAIZBORD, Boris (2009). "México y su visión estratégica de adaptación al cambio climático". En Adaptación a los impactos del cambio climático en los humedales costeros del Golfo de México (Volumen I). Secretaría de Medio Ambiente y Recursos Naturales, México. http://awsassets.panda.org/downloads/humedales_vol_1.pdf.

LIGI, Gianluca (2005). "La Inundación del Vajont. Representaciones periodísticas de un 
desastre italiano”. Desacatos, septiembre-diciembre, núm. 19, Centro de Investigaciones y Estudios Superiores en Antropología Social, Distrito Federal, México.

MANYENA, Siambabala (2006). "The concept of resilience revisited". En Disasters Journal, Vol. 30 núm 4. Overseas Development Institute, London.

MASKREY, Andrew (1993). "Los desastres no son naturales”. En Red de Estudios Sociales en Prevención de Desastres en América Latina. http://www.desenredando.org.

MEADOWS, Donella (1972) The Limits to Growth: a report for the club of Rome's project on the predicament of mankind. New York. Published by Universe Books.

MEADOWS, Donella, RANDERS, Jorgen \& MEADOWS, Dennis (2004) Los Límites del Crecimiento: 30 años después. Barcelona: Galaxia Gutenberg.

MICHELSON, Williams (1970). "Man and his urban environment: A sociological Approach, reading”. New York. MA: Addison Wesley.

OSWALD, Úrsula; SERRANO, Eréndira; FLORES, Fátima; RÍOS, Maribel; GÚNTER, Hans; RUIZ, Teresita; LEMUS, Carlos \& CRUZ, Mónica (2013). "Vulnerabilidad Social y Género entre Migrantes Ambientales”, CRIM-DGAPA-UNAM Cuernavaca.

RENDÓN, Clemente (1994) Bicentenario de Nuestra Señora del Refugio de los Esteros. Matamoros: la puerta de México, Matamoros.

ROMERO, Rafael \& CALVARIO, Norberto (1990). "Mitos y realidades de la industria de maquila”. Matamoros, El Bravo, 18 de marzo de 1990.

SIGLO XX (2013). "Los hermanos del Fierro, la dinastía de la muerte y sus corridos". En Maldito Siglo: El Desván De La Memoria. Siglo XX, México. https://malditosiglo.wordpress. com/2013/05/14/430/ consultado el 26 de octubre de 2017.

SMN (2010). “Ciclones tropicales: etapas de evolución”. Servicio Meteorológico Nacional de México, México, Comisión Nacional del Agua (CONAGUA). En http://smn.cna.gob.mx/es/ciclones-tropicales/etapas-de-evolucion consultado el 9 de febrero de 2017.

TRUJILLO, María Angélica (2006). "La resiliencia en la psicología social”. En Psicología Online. http://www.psicologia-online.com/articulos/2006/resiliencia_social.shtml consultado el 20 de octubre de 2017.

TURNER, John Kenneth (2015) México Bárbaro, México, Instituto Nacional de Estudios Políticos INEP, A. C.

ZÁRATE, Arturo (1995) “Modernización Industrial en Matamoros”, El Colegio de la Frontera Norte.

ZÁRATE, Arturo (2006) Matamoros: textos y pretextos de identidad, Matamoros, Historia. www.matamoros.com.mx/.../libro-pdf-matamoros-textos-y-pretextos-de-identidad/. 